\title{
TO DELINIATE AND OBTAIN LAND USE AND LAND COVER MAP USING SWAT MODEL IN SALEBHATA CATCHMENT OF MAHANADI BASIN
}

\author{
B.Mohan* \& C.R.Subudhi** \\ *Ex M.Tech student and Professor, Dept.of SWCE,CAET,OUAT, Bhubaneswar-751003
}

\section{ABSTRACT}

Several empirical methods and model are available to simulate the hydrological behaviour of a watershed are the more assumptive manner than the actual field value. Generally, the Geographical Information System (ArcGIS) is employed to investigate the most reliable field data along with topographic futures for watershed management and planning. In the present study physical based, semi-distributed river basin scale Soil and Water Assessment Tool (SWAT) model interface with Geographical Information System (ArcGIS) tool was used to simulate the runoff, sediment yield and to understand the sensitivity of model input parameters in Salebhata catchment area Mahanadi river basin $\left(4,588.9 \mathrm{~km}^{2}\right)$ Odisha, India. The study was conducted to delineate and find out the land use and land cover map of the Saliveta watershed under Mahanadi basin.

Key words-deliniate, land use, land cover mahanadi basin 


\section{INTRODUCTION}

Today, Food security and environment protection are the most challenging responsibility in the world. Due to continuous increasing the population growth, the optimum use of available land and water resources is crucial for improving food security. To meet the demand for food, the forest area brought under continuous intensive cultivation lead to deterioration of the quality in terms of functionally land use capability. If the degradation of the resource continues would likely affect the quantity of the environment and as a function of soil erosion. Sediment yield natural physical process is the net result of degradation and soil erosion processes associated with an excessive rainstorm, human activity, and agricultural tillage practices lead to accumulation or transporting of sediment, nutrients, and pesticides from the highest elevation to lowest position.

About $85 \%$ of land in the world is affected by soil erosion (Angima et al., 2003). In India, about 113.3 million hectares of land is subjected severely eroded to water erosion, while 69 million hectares are critically degraded due to shifting cultivation and water logging condition. About 5334 million tons of soil is being detached annually due to various reasons, as a net result of soil degradation and processes of sediment transport depends on variables that control the water and sediment yield discharge from the watershed. Therefore, for sustainable production and environmental protection and to check all these kind of deterioration and degradation of resources, some soil and water conservation measures should be taken.

It is important to predict runoff and sediment yield for planning various conservation measures, constructing structures to control soil loss and sediment mobilization in watershed scale. At the same time, lack of reliable filed and metrological data in order to adopt the suitable methods and technique to modeling the runoff and sediment yield important for applying best management practices and reliable estimation and quantify the watershed hydrological parameters response.

The SWAT model is a physical based, spatially distributed river basin model was developed by USDA Agricultural Research Service (USDA-ARS), National Resource Conservation Service (USDA-NRSC) and Texas A\&M Agri Life Research. Used to assess the long-time impact of management practices and global climate changeon soil erosion, water movement, crop growth, nutrient, pesticide yield, and non-point source pollution control, etc. with varying soil, land use and management conditions over a long period of time in the large and complex watershed (Arnold et al., 1998).

SWAT model along with GIS framework technique are employed for modeling the surface runoff, sediment load and for identifying the most critical erosionprone areas in a watershed. Such type of model can describe the physical mechanism of individual components of the hydrological process. Therefore, through the rainfall, runoff to evaluate the impact of watershed management plans 
on soil, water yield and nutrient losses. The SWAT model should be adequately evaluated effective watershed management before using them. The appropriate procedure for calibrating and validating the model for a given condition of the selected watersheds will provide appropriate management plan opportunity in a sustainable manner.

Models required to calibrate and validate in a given scenario before application. The specific information requires the SWAT about soil properties, land use and land cover map, and watershed topography for simulation. All those parameters can be derived using remote sensing (RS) and Geographic Information Systems (GIS). In SWAT, primarily the watershed is partitioned into multiple sub-watersheds or sub-basins by using Digital Elevation Model (DEM) based on the topography and specified threshold drainage area, to account land use, climate, topography, and soil type. Each sub-watershed further subdivided into a number of hydrologic response units (HRUs) that possess unique combinations of land use, vegetation cover, and soil attributes.

To assess the performance of runoff and sediment yield modeling to quantify the uncertainty inherent in the model output is important especially when the model outcomes used as a mean for applying the conservation planning and management practices in the watershed scale. Model provides the number of algorithms programs to perform the calibration process they are SUFI-2 (Sequential Uncertainty Fitting ver.2),
MCMC (Markov Chain Monte Carlo), GLUE (Generalized Likelihood Uncertainty Estimation), and Parasol (Parameter Solution) for calibration and validation, the uncertainty analysis are performing using the un-certainty program (SWAT-CUP) (Abbaspour et al. 2007). So the following objectives were taken into consideration.

\section{Objectives:}

- To delineate the watershed

- To obtain land use and l;and cover map

\section{MATERIALS AND METHODS}

This chapter deals with the description of the study area characteristics, data acquisition and method used for data processing. Overview and a brief description of the model operation, the detailed process of various datasets used in the study and provides various thematic Maps prepared under GIS environment. Procedures ware used for calibration and validation of the model are also given in this chapter.

\section{Description of the study area}

Salebhata Catchment comprising of Ong river basin, a major tributary of Mahanadi River, situated in the middle reach of Mahanadi river basin of Odisha, India was selected for the study. It coversSalebhata gauging station of the Ong catchment, and part of Balangir, Bargarh, Nuapada, Sonpur districts in the Odisha and Mahasamund district of Chhattisgarh. The catchment extending over an area of $4588.9 \mathrm{~km}^{2}$ and lies between $20^{\circ} 40^{\prime}$ '12" $\mathrm{N}$ to $21025^{\prime} 08^{\prime \prime} \mathrm{N}$ latitude and $82^{\circ} 33^{\prime} 24^{\prime \prime} \mathrm{E}$ to $83^{\circ} 24^{\prime} 11$ " E longitude as shown in Fig. 1. 


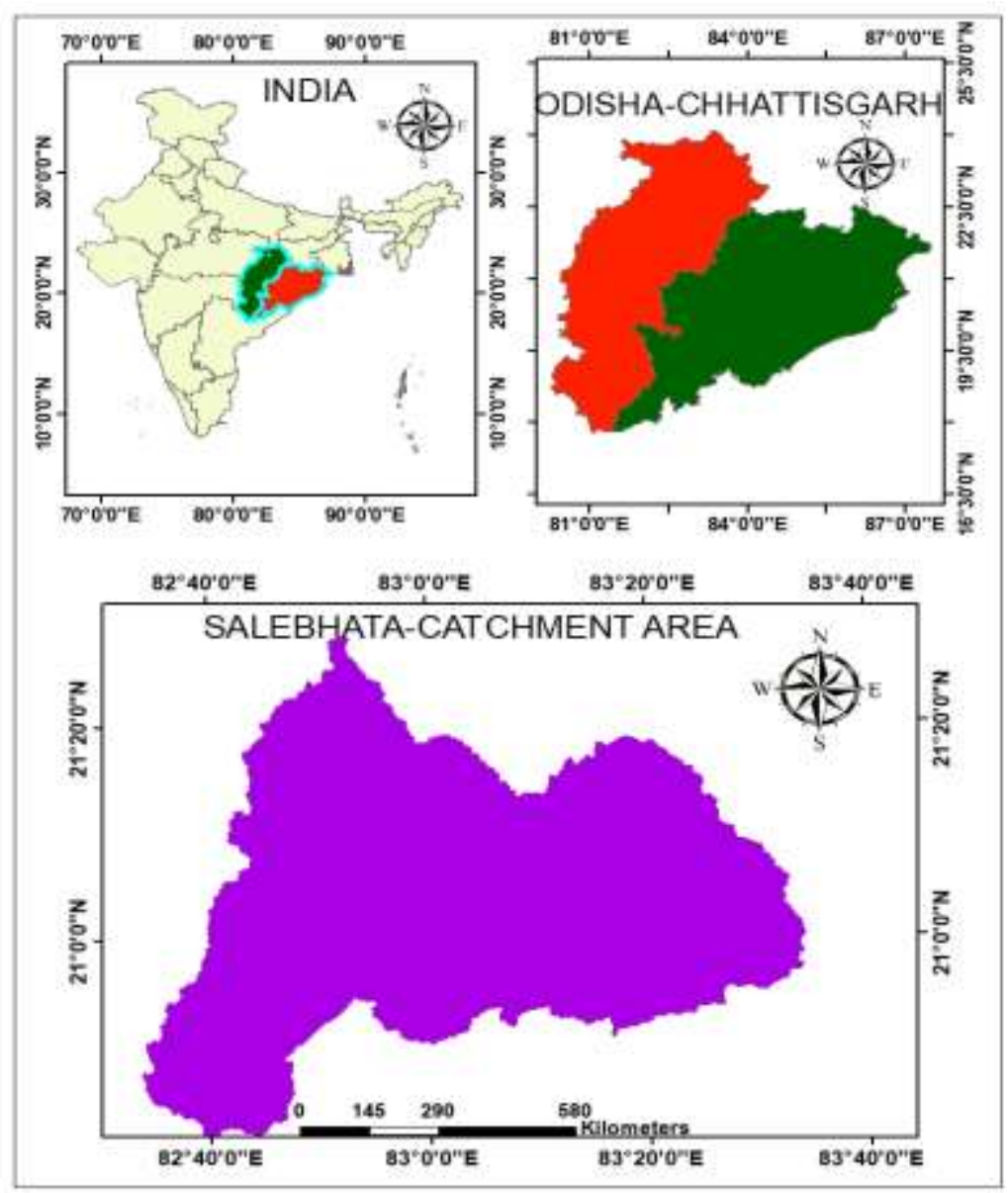

Fig. 1 Location map of the

It flows all across Odisha and joins Mahanadi in Sambalpur $11 \mathrm{~km}$ upstream of Sonpur where Tel River is merged. The river rises at an elevation of $457 \mathrm{~m}$ and runs 204 $\mathrm{km}$ before it meets Mahanadi. A major part of the study area under agricultural practices (75\%), followed by forest, paddy is the main crop grown in the cultivable land. Fig. 1 shows the Location of Salebhata catchment in Mahanadi basin at Odisha and Chhattisgarh.

\section{Software used}

\section{ArcGIS 10.3}

A geographic information system (GIS) is a combination of hardware, software, people, and methods for data capturing, documentation, indexing and displaying all forms of geographically referenced information. The ArcGIS has many component platforms allows to creating, manage, share and analysis the special spatial data and understanding and interpreting in many ways that reveal relationships, patterns in the form of maps, reports, and charts. It is a computer-based information system designed to accept a large volume of special data and allow as to store, retrieve, manipulate analyse and modeling as per user-defined specifications. The ultimate aim of the Gls is modeling to predict the soil loss and not only natural disaster also used in many sciences. ArcGIS 10 software developed by ESRI (Environmental Systems Research Institute) was used to prepare the required 
geospatial layers for the application of the hydrological model.

\section{ERDAS IMAGINE 9.3}

ERDAS IMAGINE (Earth Resource Development Assessment System), this is a raster graphics editor and remote sensing image processing application tool designed by ERDAS, Inc. it allows the user to extract the wide variety of remotely sensed image from satellite and other imaginary, as well as vector data information. It primarily aimed is to processing the geospatial raster data and allows the user to prepare, display and enhance digital images for mapping in geographic information system (GIS). The imageries are used for land use land cover and soil group classification of the targeted area.

\section{Soil and Water Assessment Tool (SWAT) Model}

Arc-SWAT is a tool in Arc-GIS software, and a graphical user interface model (Arnoldet al., 1998). It is a hydrodynamic, physical based continuous time, long time daily step and distributed parameter model was developed by USDA Agricultural Research Service (USDA-ARS), National Resource Conservation Service (USDA-NRSC) and Texas A\&M Agrilife Research. The main aim of the model is to simulate the quality and quantity of surface and groundwater. It used to predict the long-time impact of management practices and global climate change on soil erosion, water movement, crop growth, nutrient, pesticide yield, and non-point source pollution control, etc. with varying soil, land use and management conditions over a long period of time in large ungagged rural basins. The model widely used to assess the soil erosion prevention and control non-point source pollution in a watershed.

Srinivasan et al., (1994) develop the integration of a basin-scale model (SWAT) with GIS to automates inputs, to predict the effect of alternative management practices on water, sediment, and chemical yields from un-gaged rural basins. The model was developed by modifying the SWRRB model for application to large, heterogeneous rural basins.

\section{Geospatial Layers}

Geospatial layers allow to analysis and understanding special dataset namely, boundary, drainage network, reservoir, cultivation, vegetation, and soil characteristics are required for hydrological modeling of the study area. The preparation of geospatial layers of the catchment area is explained below.

\section{Digital Elevation Model (DEM)}

A digital elevation model (DEM) is an important spatial input dataset for automatic extraction of a topographical feature of the study area using automatic watershed delineation tool in Arc SWAT. According to Chaubeyet al., (2004), DEM resolution affects the watershed delineation, stream network, and sub-basin classification and as well as a decrease in DEM resolution resulted in decreased stream flow and $\mathrm{NO}_{3}-\mathrm{N}$ load predictions. In this study, a DEM map has been obtained from Space Shuttle Radar Topography Mission (SRTM) GLOBAL jointly produced by the Ministry of Economy, Trade, and 
Industry (METI) of Japan and the United States National Aeronautics and Space Administration (NASA) in the form of tiles from the world database with a resolution of $30 \mathrm{~m} \times 30 \mathrm{~m}$. Before the tile interface into the Arc SWAT, it has been mosaiced and projected into the projection coordination system. the projection UTM, spheroid type (WGS_1984) with a Datum of WGS_1984_UTM_Zone_44 N projection has been applied to DEM.

\section{Land Use/ Land Cover (LULC)}

Land use/ land cover change considerable impact on the hydrological modeling, therefore, it is important to understanding and hydrological response on climate and land use/ land cover change to proper hydrological modeling and develops suitable catchment management strategies. Land use-land cover (LULC) affects future streamflow transportation on the watershed.

In the present study, the satellite land use land covers thematic database map ware obtained from the NRSC, ISRO Hyderabad. This database map and DEM were utilized for sub-setting of satellite images were performed by taking georeferenced outline boundary of the basin as $\mathrm{AOI}$ (Area of interest). Individual agricultural land, water bodies, forest, wasteland, build up and settlements shapefiles were created in the ERDAS Imagine by using the $\mathrm{AOI}$ and signature editor tools.

\section{Spatial Data Analysis}

\section{Automatic Delineation of the Watershed}

A digital elevation model (DEM) is an important spatial input dataset in hydrological modeling to delineate the boundary, extracting stream network and slope of the watershed, DEM can be obtained from USGS Earth Explorer. The delineated watershed results in the generation of 45 sub-watersheds based on the drainage and land use pattern using ArcSWAT interference Automatic Delineation tool. The elevation of the DEM file was varied from 56 to 1007 meter from mean sea level ware obtained from the topographic report with their respective parameters of the area (Fig 2).

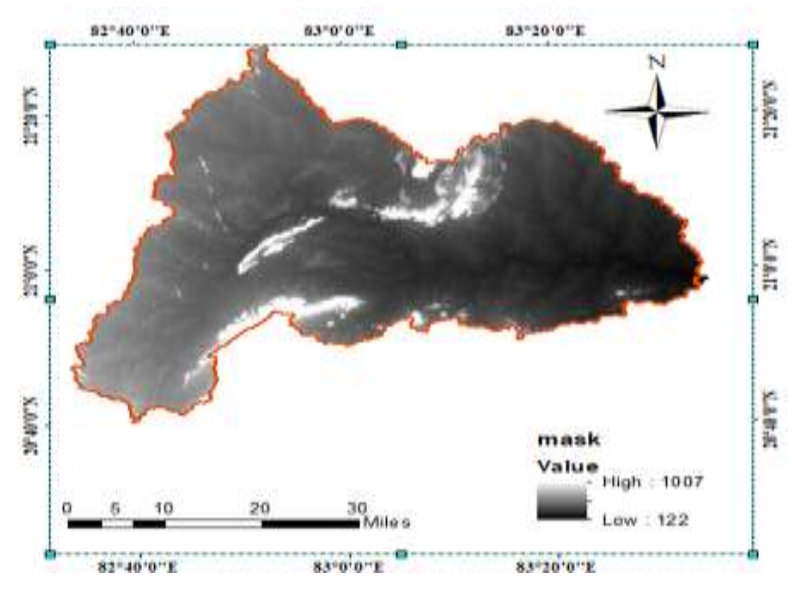

Fig. 2. Delineated watershed 
Land use/land cover

Land use/ Land cover map of the study area was obtained from NRSC, ISRO Hyderabad with a scale of 1:250000. A major part of the study area under agricultural practices, it may cover around $75 \%$ of the total catchment area followed by dense forest (16\%) and other categories ( Table 1 \&Fig 3)

Table 1 Land use type and their respective area

\begin{tabular}{|c|c|c|c|}
\hline S. No. & Land use & Area $\left.\mathbf{( k m}^{\mathbf{2}}\right)$ & $\begin{array}{c}\text { The percentage covered } \\
(\boldsymbol{\%})\end{array}$ \\
\hline 01 & Agricultural land & 3437.0861 & 74.90 \\
\hline 02 & Dense forest & 751.983043 & 16.38 \\
\hline 03 & Waterbody & 321.452445 & 7.005 \\
\hline 04 & Wetland & 67.91572 & 1.486 \\
\hline 05 & Urban land & 10.646248 & 0.232 \\
\hline
\end{tabular}

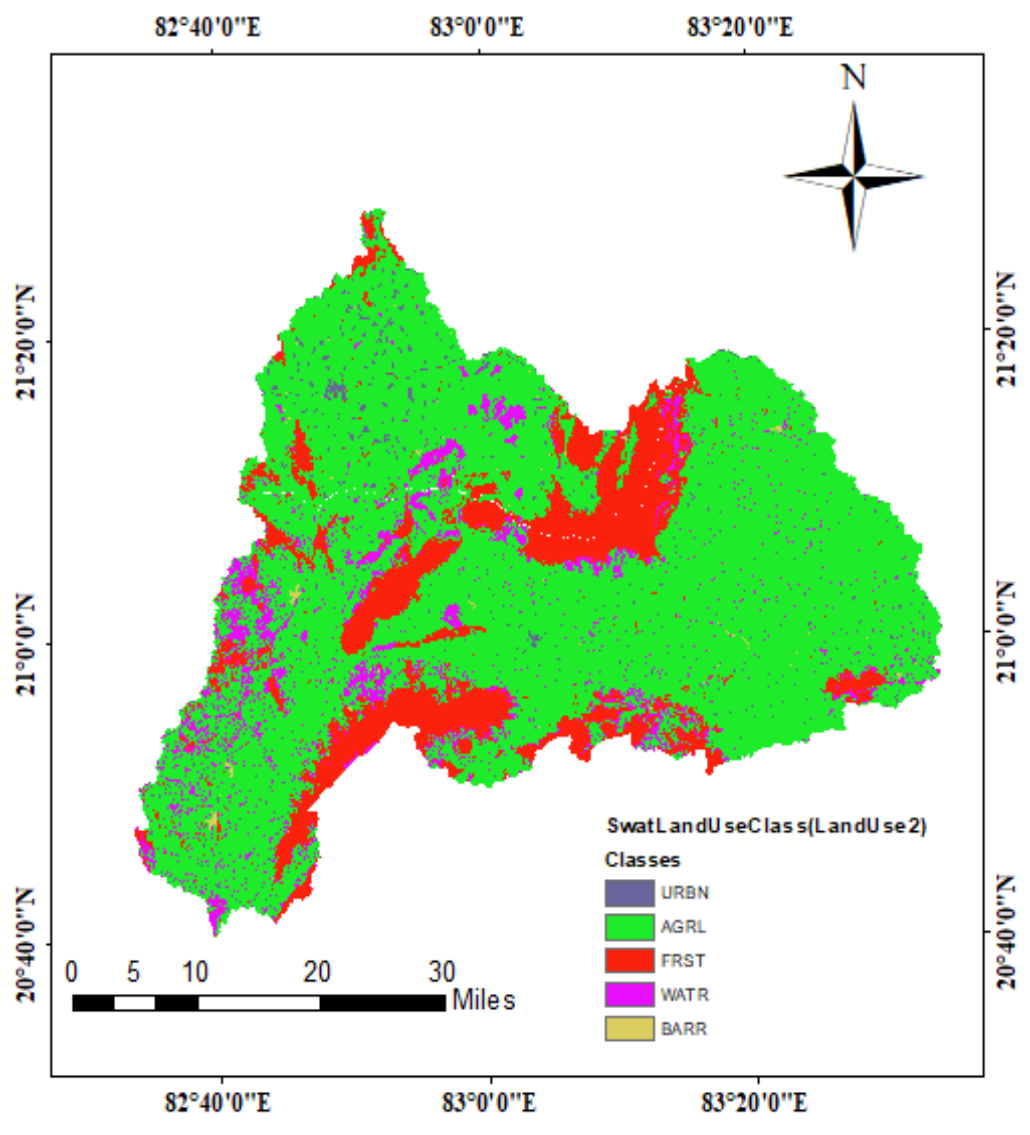

Fig.3 Study area Land use/ Land cover map CONCLUSION 
A major part of the study area under agricultural practices, it may cover around $75 \%$ of the total catchment area followed by dense forest (16\%) and other categories

\section{REFERENCES}

1. Abbaspour, K.C., Yang, J., Maximov, I., Siber, R., Bogner, K., Mieleitner, J. and Srinivasan, R. (2007). Modeling hydrology and water quality in the pre-alpine/alpine Thur watershed using SWAT. Journal of Hydrology, 333(2): 413-430.

2. Angima, S., Stott, D, O neill, M., Ong, C. and Weesies, G. (2003).Soil erosion prediction using RUSLE for central Kenyan highland conditions. Agriculture, Ecosystems and Environment, 97: 295-308.

3. Arnold, J.G., Srinivasan, R., Muttiah, R.S. \& Williams, J.R. (1998). Large area hydrologic modeling and assessment. Journal of the American Water Resources Association, 34(1): 73-89.

4. Srinvasan, R. and J. G. Arnold, J.G. (1994). Integration of a basin-scale water quality model with GIS. Water resources bulletin, Vol. 30(3): pp. 453-462. 